\title{
SAFETY CHALLENGES OF THE EUROPEAN CIVIL AVIATION IN CONDITIONS OF GLOBAL HEALTH CRISIS
}

\author{
Tomislav Tuntev, PhD \\ Civil Aviation Agency
}

Gjorgji Alceski, PhD

TAV Macedonia - Ohrid Airport

\begin{abstract}
The COVID-19 pandemic in just a few weeks has turned the whole planet upside down: from an open accessible world we have transformed into a closed fragmented particular world separated by hard transient borders. For several months, airlines in Europe suspended almost all their operations and the airports were closed for the commercial aviation. The COVID-19 crisis has caused a collapse in the air traffic and had a catastrophic impact of the airline industry and the aviation value chain. The coronavirus pandemic exposed many weaknesses across the European aviation system for which the relevant institutions did not have a quick and efficient fix.
\end{abstract}

And while we are slowly and conditionally regaining the freedom to travel within the European countries and across continents, the future of air transport is being jeopardized by this global health crisis, both in term of short-term safety and economic impact and its long-term values and responsibilities. In the field of civil aviation safety, the emphasis has shifted from the security measures against acts of unlawful interference, to measures and activities to protect the human health. All relevant international civil aviation organizations began working closely together with the most important international institutions for control of infectious diseases, in the creation of special protocols for protection against COVID-19 in air traffic. Health safety is now an intrinsic element of the aviation safety. It is very clear that air travel will never be the same again and that the air transport industry should contribute to reinventing the travel experience for the future.

Because of all this, the aim of this paper is to identify the most significant safety challenges facing the European air transport system in conditions of global health crisis. At the same time, the paper is giving some useful thoughts and recommendations for sustainable implementation of appropriate and efficient safety measures by the entities in the international and domestic aviation industry.

Keywords: aviation, air traffic, safety, crisis, health, challenges

\section{European aviation traffic decreasing due to the pandemic crisis}

\section{Flights}

Network traffic in 2020 reached unprecedented levels: 4.984.877 flights and a 55\% reduction on 2019, which means more than 6 million flights less. These extreme figures 
were due to the disruption caused by the COVID-19 pandemic on global traffic. The decline started in early March 2020 and accelerated very quickly as more mobility restrictions were enforced in Europe. The traffic in the network fell from around 26,000 at the beginning of March to a daily average of 3,500 flights in April - traffic fell by $88 \%$ that month. The situation remained unchanged in May, with an overall traffic reduction of $86 \%$. The network reached a low of 2,099 flights on 12 April. During this period, which corresponded to the 1st wave of the pandemic in Europe, about $30 \%$ of the flights were cargo operations, a segment that traditionally accounts for only $3 \%$ of the traffic. The top five pre-COVID-19airline groups were operating some $90 \%$ fewer flights. As states lifted some of the health measures at the beginning of the summer, the network showed signs of recovery with a $62 \%$ increase in traffic in June compared May. Nevertheless, the traffic levels were still 79\% below 2019 in June.

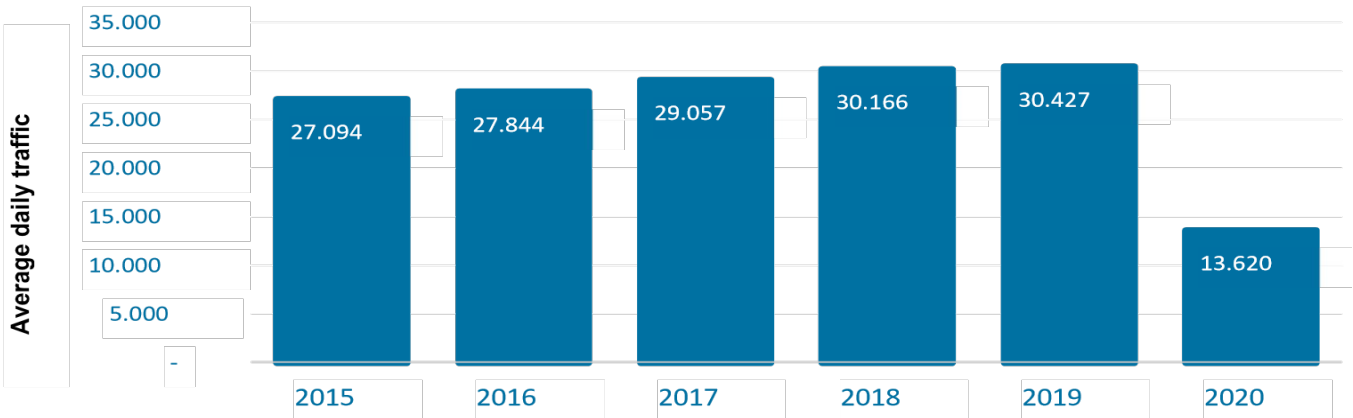

Figure 1. Average daily traffic 2015-2020 in Europe

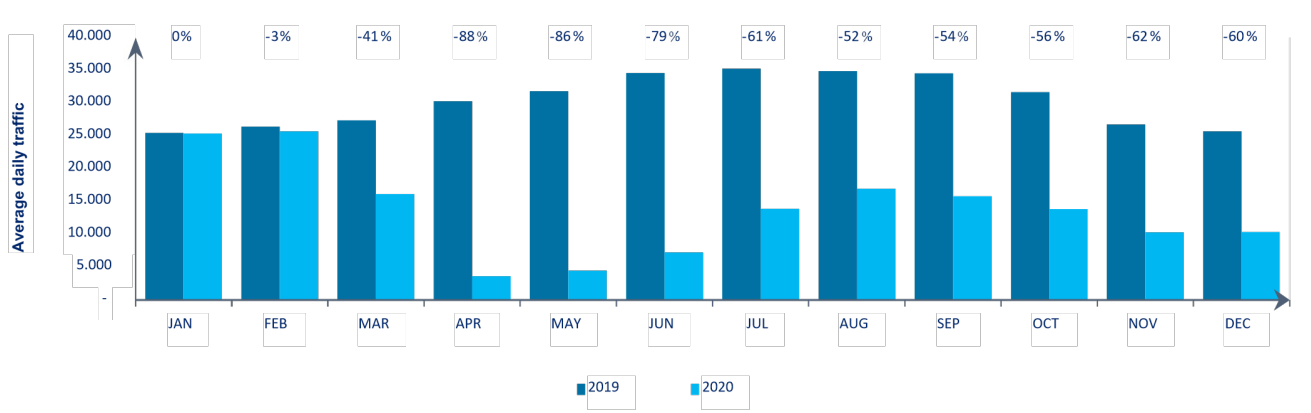

Figure 2. Average monthly traffic 2019-2020 in Europe

A more robust recovery occurred in July, with a number of airlines resuming operations and traffic doubling on the previous month. The growth continued through August with a peak of 18,802 flights (49\% of 2019) on the last Friday of the month. This was the busiest day in the network in all the COVID19 period. The health situation in Europe deteriorated at the end of the summer with renewed restrictions on travelling. It was the beginning of the second wave of the pandemic. Traffic remained at around $55 \%$ of 2019 until the start of the winter season, when many airlines revised downwards their plans. The remaining of the year 
saw increased deterioration. Despite some important boost during the Christmas period, the month of December finished with $60 \%$ decrease on traffic and just over 10,300 daily flights.

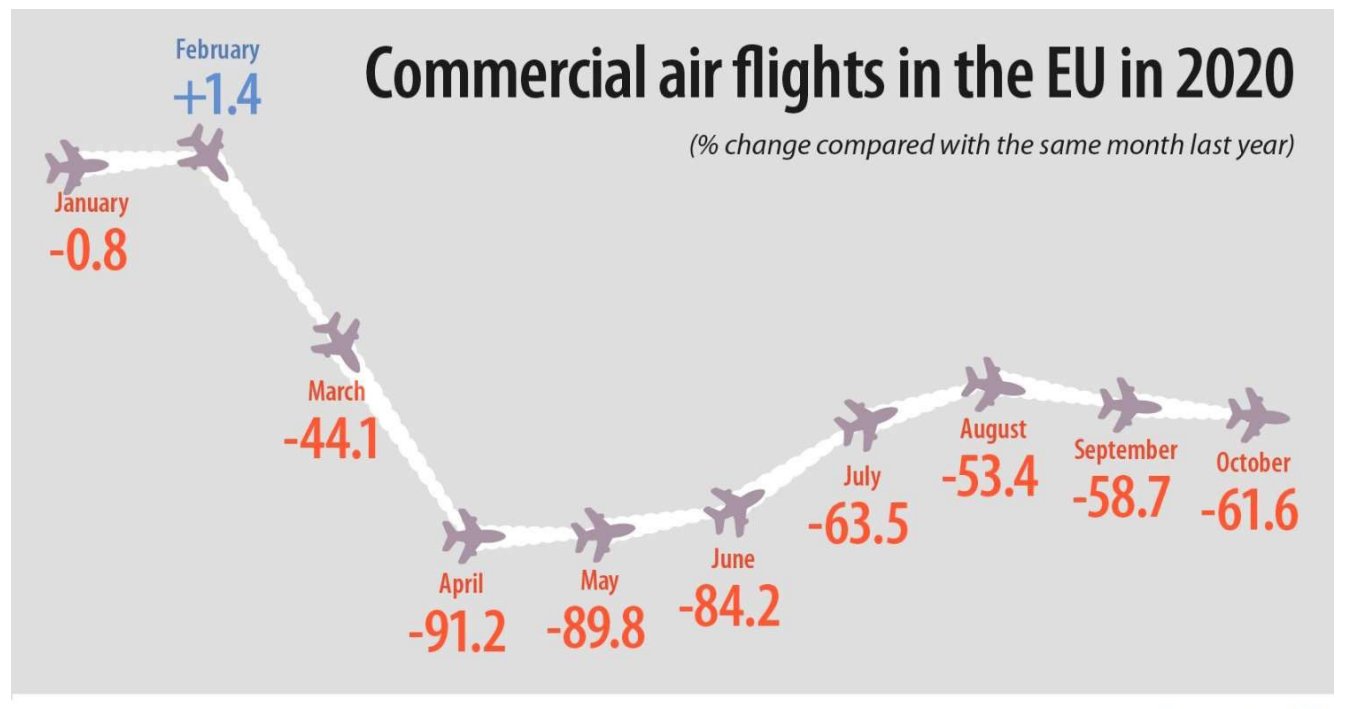

ec.europa.eu/eurostat

Figure 3. Commercial air flights in the EU in 2020

\section{Airports}

Departures from the airports in the network decreased by $55 \%$ in 2020. Average daily departures at the busiest 50 airports in Europe have dropped between -18.5\% (Leipzig/ Halle) and -71.8\% (London/Gatwick). Leipzig/Halle (DHL hub) recorded the smallest decline owing to all-cargo flights that were up by $7.8 \%$ on 2019. London/Gatwick had the largest decline partly due to low-cost flights decreasing by $69.8 \%$ at the airport that moved from $10^{\text {th }}$ in 2019 to $23^{\text {rd }}$ in 2020. The airports with the lowest decreases in traffic were mostly those where all-cargo has driven some growth: apart from Leipzig/Halle, this was also the case in East Midlands (-35.5\%) with all-cargo flights up $6.5 \%$ and KoelnBonn (-44.8\%) with all-cargo flights up $2.6 \%$ on 2019.

Amsterdam/Schiphol became the busiest airport in terms of average daily departures in 2020 (to the detriment of Frankfurt Main) with 322 daily departures, $-53.9 \%$ of 2019 flights. Paris Ch. de Gaulle moved from $3^{\text {rd }}$ in 2019 to $2^{\text {nd }}$ and recorded 302 departures per day $(-56.4 \%)$. Frankfurt Main ranked 3 rd with 290 flights per day $(-58.8 \%)$. The strong recovery of Turkish domestic flights in 2020 has lifted Istanbul/SabihaGokcen into the top 10 (from $19^{\text {th }}$ in 2019) with 170 daily departures (-45.7\%). The new ICA Istanbul airport which opened in April 2019 was the fifth busiest airport in 2020 with an average of 252 departures per day. Robust, Norwegian domestic traffic enabled Oslo/Gardermoen to rank $10^{\text {th }}$ from $14^{\text {th }}$ in 2019 and to record 167 daily departures $(-51.6 \%)$. Athens jumped from $23^{\text {rd }}$ to $11^{\text {th }}$ partly due to a rebound of holiday travel over the summer with 149 daily departures $(-50.7 \%)$. 


\section{EU airports with largest decreases in number of commercial air flights (January-October 2020)}

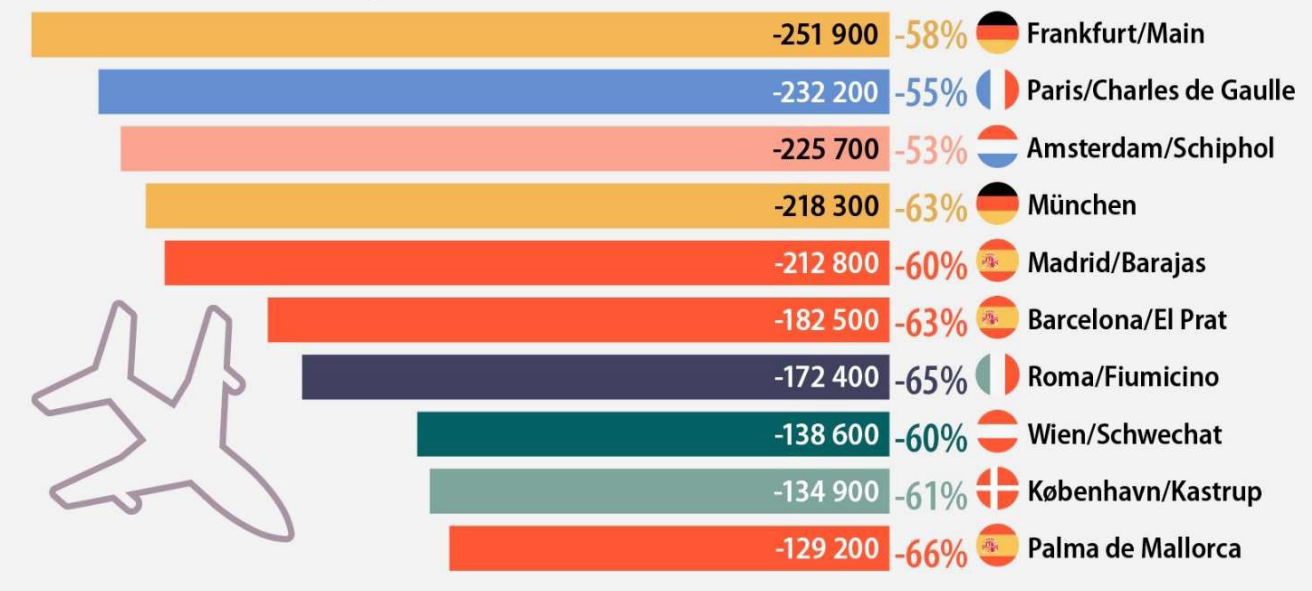

Figure 4. EU airports with largest traffic decreases in 2020

\section{Airlines}

The all-cargo and business aviation segments increased their market share in 2020 to the detriment of traditional scheduled and low-cost segments. The all-cargo segment was the least affected by the COVID19 pandemic and finished 2020 at a growth rate of $+2.3 \%$ compared to 2019. It was the only segment to record an increase in 2020 due to increased demand for medical supplies and booming e-commerce. The all-cargo segment also more than doubled its market share from $2.9 \%$ in 2019 to $6.6 \%$ in 2020 due the loss of belly-hold capacity in passenger aircraft. In April and May when almost all traffic came to a standstill (-87.1\% on average), all-cargo remained robust and was down by $-5.9 \%$ on average. The segment surged to a double-digit increase $(+10.8 \%)$ in December 2020 (vs. December 2019) boosted by COVID-19 vaccine flights.

The low-cost segment operated the fewest flights during the second quarter of 2020 (-96.2\% on average vs. 2019) as low-cost airlines were less involved in repatriation and cargo operations. It was the worst-hit of all the segments in April but it re-started quicker than traditional scheduled airlines over the summer $(59.1 \%$ on average vs. $-65.8 \%$ for traditional scheduled) boosted by leisure travel. A lack of harmonization of renewed travel restrictions in Europe from October onwards led to an average decrease of $73.8 \%$ for the rest of the year. Overall, low-cost flights were down by $64.1 \%$ in 2020 , corresponding to 2.1 million flights lost compared to 2019.

The traditional scheduled segment declined by $-60.7 \%$ with flights down by 3.6 million in 2020 (vs. 2019) and was less affected than low-cost during the April-June period as it was operating some repatriation flights as well as (passenger) cargo transportation. The segment recovered more slowly during the summer July-September but ended 2020 above low-cost traffic levels at $-66.2 \%$ on average (vs. $-73.8 \%$ for the low-cost segment). 
COVID-19 saw the emergence of video-conferencing as a business communication solution, which resulted in less corporate business travel and impacted airlines business traffic.

The business aviation segment decreased by $-24.4 \%$ in 2020 compared with 2019 . Flights were down $70.8 \%$ at the lowest point in April but recovered from June when travel restrictions were lifted to ensure connectivity where connections operated by scheduled carriers were unavailable. In August, business aviation was back to 2019 levels (+ $0.3 \%$ vs August 2019). Its market share went from $6.4 \%$ in 2019 to $10.7 \%$ in 2020.

The charter segment (non-scheduled flights) was down by $-41.5 \%$ in 2020 (vs. 2019) although it recovered from June onwards, from $-59.4 \%$ to $-12.2 \%$ in December and was the only segment, along with all-cargo to continue growing in November and December 2020. The charter segment also improved its market share from $4.0 \%$ in 2019 to $5.2 \%$ in 2020. Noted that the charter segment has captured a portion of flights usually operated by traditional scheduled passenger carriers for cargo operations.
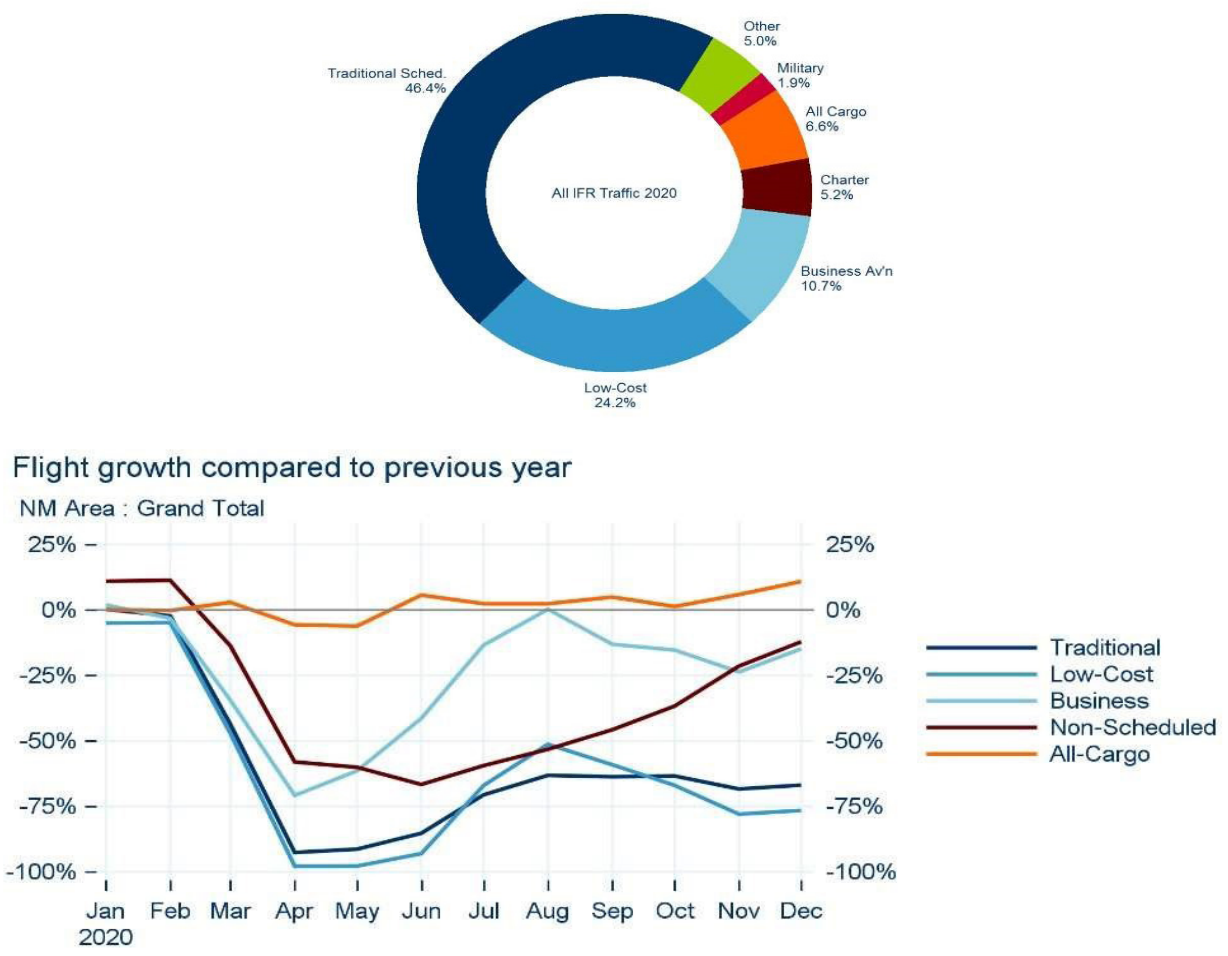

CEUROCONTROL 2021 mww. eurocontrol. int/STATFOR

Figure 5. Market segment's share and Market segment's growth in 2020 in Europe.

\section{European aviation industry challenges}

COVID-19 has been an unprecedented calamity for European aviation and its effect will be present many years to come. Just till now there are over 6 million flights and more than 1.5 billion fewer individual journeys. Tens of thousands of jobs have already 
been lost and an estimated 6 million more remain at risk. The overall loss to the aviation industry in 2020 has been estimated at over $€ 140$ billion.

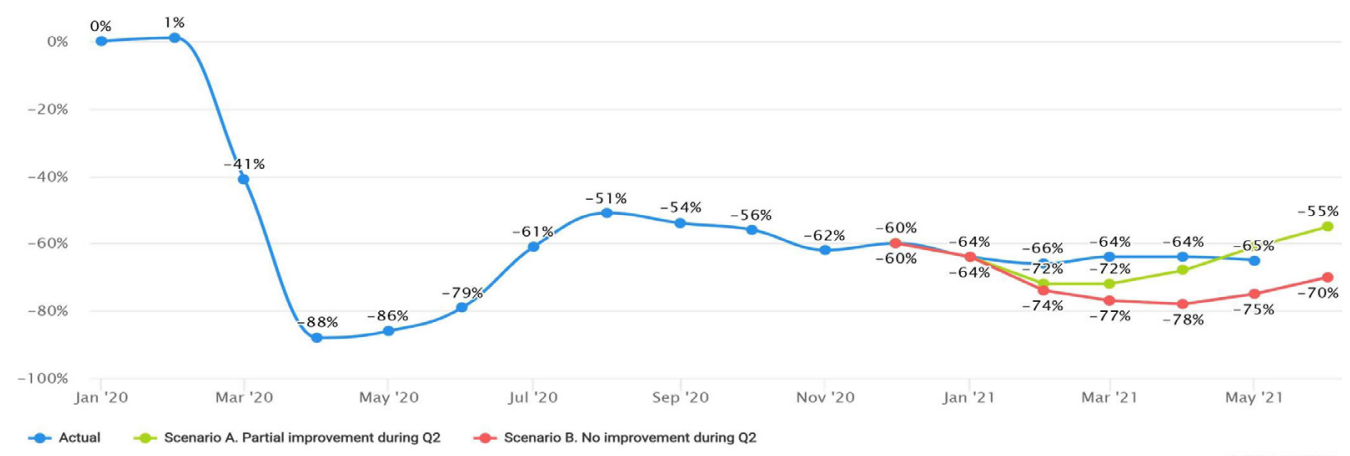

Figure 6. EUROCONTROL Draft Traffic Scenarios - 28 January 2021 (base year 2019)

All European aviation partners have worked really hard last year to enable a smooth recovery. However, the situation since the last summer has shown that passenger confidence is heavily dependent on State decision-making. Faced with ever-changing color codes for destinations and the risk of quarantine going out or returning, many have opted to stay at home. Put simply, quarantines are a killer for the aviation industry. Unfortunately, all different states have responded to a resurgence in the pandemic by imposing a bewildering and rapidly changing set of travel restrictions. More coordination and the decision by the European Council to put in place a common map identifying the level of risk across the Europe is more than welcomed for the aviation industry recovery. This is vitally needed, both for greater understanding and acceptance of restrictions by the public and also for the aviation industry, which is finding it increasingly difficult to plan ahead. Furthermore, a greater coordination in the approach taken by States to testing - both before and after travel is needed. Greater availability and use of testing would really help to make travel possible for people who have a pressing need to travel but who are prevented from doing so by the need to quarantine either in the destination country or on their return.

For aviation, one prediction that can be made with confidence is that the entire industry will not be the same in the future as it was before the pandemic. Any hopes that COVID-19 could pass with few months of temporary interruption of normal business have been dashed - and deep-rooted change is inevitable. It is now essential to keep proving that air travel can continue safely by maintaining a focus on the rules and processes that have made flying the safest way of transport. In the same time, there is need to identify and embrace sweeping change in aviation industry, to ensure it emerges stronger and is able to cope with new challenges that will undoubtedly arise.

The longer-term challenges facing the industry are huge. Aviation cannot emerge unscathed from this crisis and needs, wherever possible, to use it as a catalyst for change. Safety and security are long-accepted pillars of the aviation industry. The pandemic demonstrated all too painfully that health safety is now a third pillar that can pose an at least equal threat. So, the health safety is now an intrinsic element of aviation safety. In addition to the detail financial hits taken by airports and airlines as passengers stopped flying, the 
crisis threw into question some fundamental aspects of the industry's financial framework. Financial sustainability for the aviation industry is also one of the most important question for all partners. Then, a green recovery today is more important than ever. At the start of 2020, the need to make aviation sustainable and greener was top of the agenda. It is still up there, temporarily eclipsed by the more immediate health problems. While the crisis has led to the mothballing or retirement of an unprecedented number of old, fuel-hungry aircraft, it has done nothing to encourage the industry to invest in more fuel-efficient replacements. The industry needs to be able to respond firmly with counter-arguments and demonstrable actions that make flying more sustainable. Any crisis presents a lot of opportunities. The main challenge is to find the resources and energy for the aviation sector to project itself into a new era. In the air traffic management sector in particular, it is widely accepted that the systemic capacity of European air navigation service provision can only be increased through the adoption of new technologies. It is now, while traffic is still down, that investments must be made into the necessary technological leap for air traffic management.

\section{European aviation industry challenges}

COVID-19 has been an unprecedented calamity for European aviation and its effect will be present many years to come. Just till now there are over 6 million flights and more than 1.5 billion fewer individual journeys. Tens of thousands of jobs have already been lost and an estimated 6 million more remain at risk. The overall loss to the aviation industry in 2020 has been estimated at over $€ 140$ billion.

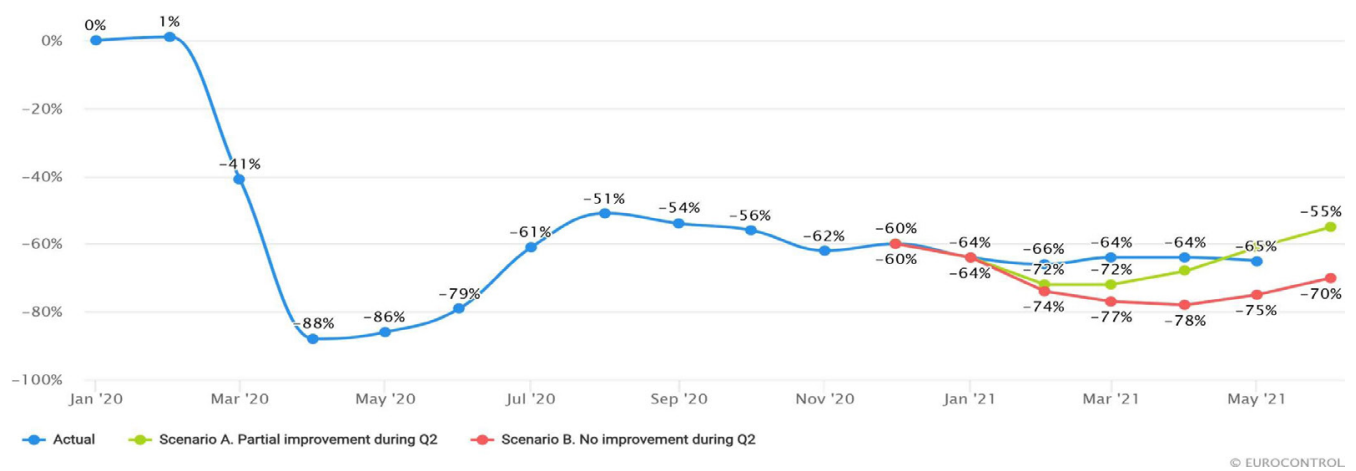

Figure 6. EUROCONTROL Draft Traffic Scenarios - 28 January 2021 (base year 2019)

All European aviation partners have worked really hard last year to enable a smooth recovery. However, the situation since the last summer has shown that passenger confidence is heavily dependent on State decision-making. Faced with ever-changing color codes for destinations and the risk of quarantine going out or returning, many have opted to stay at home. Put simply, quarantines are a killer for the aviation industry. Unfortunately, all different states have responded to a resurgence in the pandemic by imposing a bewildering and rapidly changing set of travel restrictions. More coordination and the decision by the European Council to put in place a common map identifying the level of risk across the Europe is more than welcomed for the aviation industry recovery. This is vitally needed, both 
for greater understanding and acceptance of restrictions by the public and also for the aviation industry, which is finding it increasingly difficult to plan ahead. Furthermore, a greater coordination in the approach taken by States to testing - both before and after travel is needed. Greater availability and use of testing would really help to make travel possible for people who have a pressing need to travel but who are prevented from doing so by the need to quarantine either in the destination country or on their return.

For aviation, one prediction that can be made with confidence is that the entire industry will not be the same in the future as it was before the pandemic. Any hopes that COVID-19 could pass with few months of temporary interruption of normal business have been dashed - and deep-rooted change is inevitable. It is now essential to keep proving that air travel can continue safely by maintaining a focus on the rules and processes that have made flying the safest way of transport. In the same time, there is need to identify and embrace sweeping change in aviation industry, to ensure it emerges stronger and is able to cope with new challenges that will undoubtedly arise.

The longer-term challenges facing the industry are huge. Aviation cannot emerge unscathed from this crisis and needs, wherever possible, to use it as a catalyst for change. Safety and security are long-accepted pillars of the aviation industry. The pandemic demonstrated all too painfully that health safety is now a third pillar that can pose an at least equal threat. So, the health safety is now an intrinsic element of aviation safety. In addition to the detail financial hits taken by airports and airlines as passengers stopped flying, the crisis threw into question some fundamental aspects of the industry's financial framework. Financial sustainability for the aviation industry is also one of the most important question for all partners. Then, a green recovery today is more important than ever. At the start of 2020, the need to make aviation sustainable and greener was top of the agenda. It is still up there, temporarily eclipsed by the more immediate health problems. While the crisis has led to the mothballing or retirement of an unprecedented number of old, fuel-hungry aircraft, it has done nothing to encourage the industry to invest in more fuel-efficient replacements. The industry needs to be able to respond firmly with counter-arguments and demonstrable actions that make flying more sustainable. Any crisis presents a lot of opportunities. The main challenge is to find the resources and energy for the aviation sector to project itself into a new era. In the air traffic management sector in particular, it is widely accepted that the systemic capacity of European air navigation service provision can only be increased through the adoption of new technologies. It is now, while traffic is still down, that investments must be made into the necessary technological leap for air traffic management.

\section{European airlines challenges}

Airlines will continue to connect continents and people, economies and cultures, because they play an essential role in sharing knowledge and in the perpetual progress of our global society. It is impossible to imagine the world we dream of without air transport. However, the crisis facing our industry will help to rethink the way it works, even reinventing itself in several respects. The aircraft is the safest means of transport. Since its origins, players across the aviation industry have been pioneers in the field of safety, developing and sharing new technologies to make air travel ever more reliable. Today, the concept of 
aviation safety must be extended to include health and hygiene, to assume a vital new responsibility in the world that is opening new frontiers.

While the need for environmental stewardship has become increasingly obvious, the demands of governments, as well as of their citizens, have become ever more rigorous. That's good, because it's essential to respond to the immense climate challenges ahead of us by collectively exploring all avenues to reduce greenhouse gases, noise pollution and all forms of negative environmental impact.

The entire air transport ecosystem must make a joint commitment: airlines must promote biofuels and develop eco-piloting, with a fleet of more modern aircraft. Aircraft and engine manufacturers, too, are reducing their carbon footprint through innovation and construction processes and developing more fuel-efficient aircraft components. The most efficient aircraft are no longer the largest, and priority is being given to the latest generation of aircraft, such as the Airbus A350, A220 and the Boeing 787, which are marking the end of the four-engine aircraft era sooner than expected.

While air travel has become rather routine, passengers are now questioning the relevance of such a travel solution: why take the plane and not the train or a car? Why even travel when global lockdown has proven the effectiveness of videoconferencing? Which airline can best meet passengers' new aspirations? Faced with these unprecedented questions from the customers, airlines will have to transform the experience they offer them. The travel experience must be re-thought: from flexibility during booking to the consumption of local produce on meal trays, and from the elimination of plastic on board to frequent flyer programs offering "environmental miles". In this new pattern, it is the most responsible airlines that will prove resilient in this historic crisis, because they will be the ones who rewrite the future of air travel and adapt to a new travel reality.

One is certain - air travel will never be the same again for the airlines. Near the beginning of the COVID19 crisis, several airlines disappeared within a few weeks. The consolidation of the sector is likely to accelerate, as well as new alliance strategies that will help restore profitability in a sector now affected by new challenges. The industry has done a good job to safely keep our world connected during the COVID19 crisis. But operations are still far from normal and many challenges remain. These are challenges that should be shared with governments: avoiding the importation of COVID-19 through travel and restoring people's freedom of movement and repairing the economy. To keep COVID-19 outside their countries, many governments have simply closed their borders. Others kept their borders open but imposed quarantine on travelers. The effect is the same - it halts travel, so there is not any progress in restoring the fundamental right of movement and the travel and tourism economy is effectively stopped. People must learn to live with this virus, despite the expected vaccine positive effect. The stop-go-stop approach to lifting and reposing restrictions does not bring us closer to that, nor will it enable economic recovery. The aviation industry is still living through a crisis, and as it emerges it will have to align the aspirations of customers and global citizens everywhere with redesigned and renewed products and services. It is only by resolutely committing to this transformation that the air transport industry will contribute to reinventing the travel experience for the twentyfirst century. 


\section{European airports challenges}

Airports without passengers and without airplanes make no sense. That's why the fast recovery measures and addressing the weaknesses that the crisis exposed, must also go hand in hand with the structural reforms that were already needed pre-coronavirus. They will not disappear, so the airport executives need to address them as soon as possible. There is no other choice but to turn the crisis into an opportunity to make the sector more resilient and more sustainable.

People need airports that can obtain the benefits of digitalization and automation. The relevant international aviation organizations made some studies to help airports to plan their post-pandemic actions to improve performance when implementing COVID-19 measures. These studies assessed the impact of such measures on terminal operations, in particular passenger journey time, terminal throughput and boarding gate processing capacity.

The result show that, for the same passenger numbers in a pre-COVID queue:

- $50 \%$ more space is required at check-in;

- $100 \%$ more space is required at security control;

- $\quad 35-50 \%$ more space is required at boarding gates;

- Up to 10 minutes' additional time to the departing passenger journey;

- $100 \%$ more space is required at immigration;

- $\quad 30-50 \%$ more space is required for baggage reclaim;

- 5-20 minutes' additional time to the arriving passenger journey;

- Additional measures are needed to mitigate impact of health checks are required for arrivals.

Airports should focus on key limiting components - security control and immigration in terms of throughput challenges, and boarding gates and baggage reclaim in terms of space constrains. The airports that were already congested before the COVID crisis can expect to reach their maximum saturation capacity at just $60-75 \%$ of their peak 2019 traffic. To avoid further delays and conflicting requests to passengers, greater harmonization in terms of COVID measures supporting passenger safety and rebuilding trust is essential across EU Member States, as well as the rest of the European countries.

\section{European air navigation service providers challenges}

The deferral of air traffic control (ATC) charges by airlines and securing financial aid for to help ensure the liquidity of the industry are the greatest challenges for the European air navigation service providers (ANSPs). It became clear that no one partner can navigate the industry's future on its own. Air traffic management (ATM) cannot bankroll operations, nor can airports fund prime aviation facilities, just as airlines cannot shore up much-needed passenger demand and revenue with ongoing travel restrictions. Looking ahead, the aviation industry will have to continue to grapple with changing attitudes to air travel, competing priorities for state support, and the ongoing problem of reducing costs without hindering efficiency, innovation and skills. It therefore needs to find ways to work cross-sector to reduce gaps in coordination 
and deliver a strong model for the future. Cooperation is vital in mapping out the industry's future - whether that be implementing legislative change such as the Single European Sky (SES) in Europe or improving performance.

The best way the industry could manage the crisis and then plan a coordinated recovery would be to work collectively to share data on airline schedules and capacity. It developed a new concept for initially a business continuity and afterwards a recovery plan, which included weekly conference calls sharing consolidated information on expected traffic and capacity delivery levels for the ensuing four weeks, extended afterwards to six weeks. It is an unprecedented effort by all stakeholders to coordinating with and receiving information from 140 airports, 68 en-route ATC units and 320 airlines, consolidating information on flight schedules and capacity to provide a traffic and capacity outlook. Safety, military and major events planning information is also updated weekly. The only source who could have provided this consolidated information is just EUROCONTROL Network Manager (NM), as a main developer of unifying crisis management and recovery strategy for European aviation.

To support this tremendous effort, an average 700 to 800 notification amendments a day should be monitored, each of which had an impact on the European traffic situation. This took at least one major task away from the beleaguered airlines and meant all stakeholders could plan their crisis management and recovery operations on the basis of consolidated and trustworthy data. NM staff also swiftly developed "best-practice" procedures for ATC staff to work safely, so new work practices could be included in crisis management plans. ANSPs faced critical staffing issues: flight numbers may have been reduced by more than $50 \%$, but that didn't mean controller numbers could be reduced by the same amount. Demand continued to be volatile and ANSPs had to build in capacity for sudden surges. Included in the NM's recovery plan is a requirement to identify where and how capacity could be added into the system as the recovery slowly gained hold. For ANSPs it means they could introduce COVID-19 protection measures based on more accurate estimate of how many controllers would be working and which sectors would be open.

Planning the recovery for the ANSPs is a complex task and will require further and deeper stakeholder coordination. For example, controllers will have temporarily lost some degree of skill at handling complex traffic loads and it will take time to ramp up capacity levels to pre-COVID-19 performance. It has become clear that a network operating close to its capacity has a very different environmental performance to a network where traffic levels are much reduced - adding just one or two flights to a constrained network increases $\mathrm{CO}_{2}$ emissions over a very wide area. So managers are using the breathing space which the pandemic has delivered to rethink the way capacity can be managed, via the operational excellence program, so a much more coordinated approach to capacity management can be developed among all stakeholders. For example, many of the previous restrictions which ANSPs regularly built into the system can now identified as not being required.

\section{European civil aviation regulators challenges}

The national supervisory aviation authorities (NSAs), or national civil aviation regulatory bodies, have to ensure that the aviation sector in their own countries receives the best possible support during these difficult times. For grants and loans to national aviation 
sector, each NSA should make serious efforts to convince state governments to invest ensuring that taxpayers' money targets sustainable investment.

The main challenges for aviation before the pandemic were to become sustainable and to address a lack of capacity. The sustainability challenge has not disappeared, and recovery needs to take that into account. Sustainable growth is essential across the entire transport sector once we are out of the COVID-19 crisis. In the face of COVID-19, extra measures must be taking, implemented and maintained within the national air transport system. Those measures have given governments a solid basis to restart aviation and go a long way to addressing travelers' main concerns about sanitization and human interaction. The outcomes of this work are clearly visible:

- Mandatory wearing of face masks at both the airport and onboard;

- Increased sanitization of the key airport and aircraft touch points;

- Enabling social distancing at departure and arrival and on board in terms of queuing for lavatories;

- Reduced service on board;

- Promotion of contactless processes that minimize human interaction.

However, maybe the most important effort of all NSAs is to convince their own governments, health authorities and decision makers to promote and to apply harmonized, unified and coordinated approach in the process of cooperation with other countries to establish common standards, recommendations and practices for anti-COVID protection measures and activities. Avoiding the importation of COVID-19 through travel, restoring people's freedom of movement and repairing the economies are the challenges that every particular NSA share with the government. To keep COVID-19 outside their countries, many governments have simply closed their borders. Others kept their borders open but imposed quarantine on travelers. The effect is the same - it halts travel, so there is not any progress in restoring the fundamental right of movement and the travel and tourism economy is effectively stopped. That's why everybody must learn to live with this virus. The Stop-Co-Stop approach to lifting and reposing restrictions does not bring us closer to that, nor will it enable economic recovery.

Some European governments and health authorities becoming more precise and targeted with preventative measures because it is clear that they must limit any return to widespread lockdowns and the economic and social damage they cause. In this situation, the behavior of the general public - wearing of masks, social distancing and continued hand sanitization - is crucial. From an aviation standpoint, the NSAs, together with the partners in the aviation industry, have to have on mind the passengers feeling ill not to travel, and many ticket options offer a no-penalty cancellation if the passenger suspects they might have COVID-19.

It is also becoming increasingly apparent that COVID-19 testing will need to play a role in facilitating travel. There are already tests that are accurate enough to be used to facilitate the relaxing of travel restrictions. Testing at the start of the travel process would create a "sterile" travel environment to reassure travelers and governments, and could be an effective risk equalization measure to support the reopening of borders between countries where there is significant asymmetry in infection rates. Of course, the process of mass 
immunization by vaccination should have the biggest impact to gradual normalization of the travel by the air and the aviation and air traffic in generally.

\section{Swiss cheese model for anti-COVID protection in aviation}

Swiss cheese model of accident causation is a model used in risk analysis and risk management, including aviation safety, engineering, healthcare, emergency service organizations, and as the principle behind layered security, as used in computer security and defense in depth. It likens human systems to multiple slices of Swiss cheese, stacked side by side, in which the risk of a threat becoming a reality is mitigated by the differing layers and types of defenses which are "layered" behind each other. Therefore, in theory, lapses and weaknesses in one defense do not allow a risk to materialize, since other defenses also exist, to prevent a single point of failure. The model was originally formally propounded by James T. Reason of the University of Manchester in the 1990s, and has since gained widespread acceptance. It is sometimes called the "cumulative act effect".

At the end of October 2020, Australian virologist Prof. Ian Mackay tweeted about the Swiss cheese model as a multi-layered approach for combatting COVID-19. His tweet went viral. This layered approach to reducing risk related to human error in relation to accidents is adapted to become relevant to the way in which we stack up COVID-19 preventive measures to maximize our protection against infection. And, also to show how no preventive measure - from mask wearing to hand washing and even to receiving a COVID-19 vaccine - is perfect at protecting people from being infected with COVID-19, or passing it on to others, on its own. That's why a multiple preventive behavior at the same time must be practiced. And, it's also why having a COVID-19 vaccine does not mean an end to the preventive measures we have practiced for months, to limit the spread of COVID-19 and protect ourselves from exposure to the disease.

\section{THE SWISS CheESE RESPIRATORY VIRUS PANDEmic DEfence}

RECOGNISING THAT NO SINGLE INTERVENTION IS PERFECT AT PREVENTING SPREAD

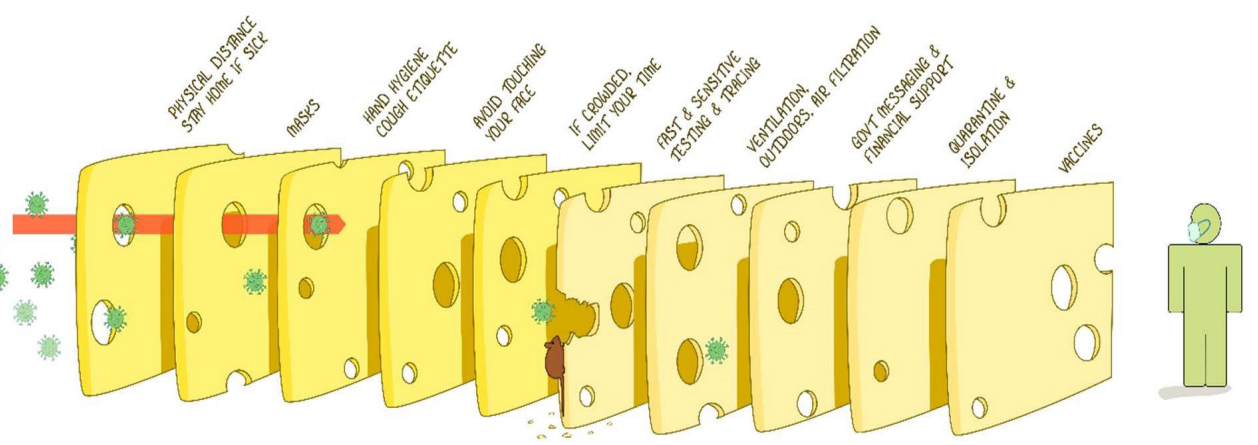

PERSONAL RESPONSBBLIITIES

SHARED RESPONSIBILITIES

EACH INTERVENTION (LAYER) HAS IMPERFECTIONS (hOLES).

MULTIPLE LAYERS IMPROVE SUCCESS.

Figure 5. Swiss cheese virus pandemic defense model 
The so-called "Swiss cheese respiratory virus pandemic defense" recognizes that no single intervention is perfect at preventing the spread of COVID-19. It's important that everybody takes its own personal and shared responsibilities for preventing the spread of infection seriously. The model's main point or the basic assumption is that in our actions there are holes. When people wear masks, for example, they make holes in this protective behavior choosing a mask that is too thin, not wearing mask correctly, touch it with unclean hands, sharing mask, using the same mask for a longer time without proper cleaning and washing, disposing mask improperly, and so on. The metaphor is easy enough to grasp: multiple layers of protection, imagined as cheese slices, block the spread of the coronavirus COVID-19. No one layer is perfect; each has holes, and when the holes align the risk of infection increases. But several layers combined - social distancing, plus masks, plus hand-washing, plus testing and tracing, plus ventilation, plus government messaging - significantly reduce the overall risk. Vaccination will add one more protective layer. This model is applicable in the aviation industry, within all entities and partners.

The model groups the specified activities in two responsibility areas:

Within personal responsibilities:

- Wearing masks;

- Staying at home when sick;

- Practicing physical distancing;

- Washing our hands frequently for at least 20 seconds with soap and water;

- Practicing cough and sneeze etiquette - cough or sneeze into a flexed elbow or tissue, and discard it safely immediately;

- Avoiding touching face;

- Avoiding crowds of people.

- Within shared responsibilities:

- Should we develop symptoms of COVID-19 ensuring that we access healthcare responsibly to confirm our diagnosis and assisting healthcare professionals to carry out effective contact tracing;

- Ensuring we quarantine for 10 days when exposed to someone who has COVID-19 and self-isolate for 10 days when we contract COVID-19;

- Ensuring there is ventilation when we meet with others and meeting with others outdoors where ever possible;

- Taking government communication about the pandemic to heart and supporting national COVID-19 effort;

- Being vaccinated against COVID-19;

- Effective monitoring of COVID-19 at country borders.

All in all, this model serves as a great reminder that the many preventive behaviors that we put in place every day - all the behaviors and strategies listed above - have their imperfections on an individual basis - and are not perfect alone. However, collectively they are very effective in giving us greater protection against infection with COVID-19. Along the same lines, COVID-19 vaccines are not the ultimate solution to ending the COVID-19 pandemic. They are a very important part of the solution - another layer in the Swiss cheese of protective barriers available to everybody. 
The real power of this model is that it's not really about any single layer of protection or the order of them but about the additive success of using multiple layers, or cheese slices. Each slice has holes or failings, and those holes can change in number and size and location, depending on how we behave in response to each intervention. To be as safe as possible and to keep those around us safe, it's important to use more slices to prevent those volatile holes from aligning and letting virus through.

In the Swiss cheese model, an organization's defenses against failure are modeled as a series of barriers, represented as slices of cheese, specifically Swiss cheese with holes known as "eyes", such as Emmental cheese. The holes in the slices represent weaknesses in individual parts of the system and are continually varying in size and position across the slices. The system produces failures when a hole in each slice momentarily aligns, permitting "a trajectory of accident opportunity", so that a hazard passes through holes in all of the slices, leading to a failure. Reason hypothesized that most accidents can be traced to one or more of four failure domains: organizational influences, supervision, preconditions, and specific acts. In aviation, preconditions for unsafe acts include fatigued air crew or improper communications practices. Unsafe supervision encompasses for example, pairing inexperienced pilots on a night flight into known adverse weather. Organizational influences encompass such things as reduction in expenditure on pilot training in times of financial austerity.

\section{Conclusion}

The COVID-19 crisis has caused a collapse in the air traffic and had a catastrophic impact of the airline industry and the aviation value chain. The coronavirus pandemic exposed many weakness across the European aviation system for which the relevant institutions did not have a quick and efficient fix. COVID-19 has been an unprecedented calamity for European aviation and its effect will be present many years to come. We have seen just over 6 million flights and more than 1.5 billion fewer individual journeys. Tens of thousands of jobs have already been lost and an estimated 6 million more remain at risk. The overall loss to the aviation industry in 2020 has been estimated at over $€ 140$ billion. In the field of civil aviation safety, the emphasis has shifted from the security measures against acts of unlawful interference, to measures and activities to protect the human health. It is very clear that air travel will never be the same again and that the air transport industry should contribute to reinventing the travel experience for the future.

All European aviation partners have to work very hard to enable a smooth recovery. Usually, every different state has responded to a resurgence in the pandemic by imposing a bewildering and rapidly changing set of travel restrictions. Quarantines, closed borders, travel restrictions, isolations and other restrictive unilateral and uncoordinated measures are detrimental, or better said disastrous, for the aviation industry. That's why the efforts of the relevant European aviation organizations and associations, in pushing for more coordination and the decision by the European Council to put in place a common map identifying the level of risk across the Continent, are more than welcomed. This is vitally needed, both for greater understanding and acceptance of restrictions by the public and also for the aviation industry, which is finding it increasingly difficult to plan ahead. The most important effort is to convince the governments, health authorities and decision makers to promote and to apply harmonized, unified and coordinated approach in the process of cooperation, to establish 
common standards, recommendations and practices for anti-COVID protection measures and activities.

Some universal models of accident causation based on layered approach, used in risk analysis and risk management, could be successfully applied in the aviation industry to help anti-virus protection. The layered approach to reducing risk related to human error in relation to accidents could be adapted to become relevant to the way of stacking up the COVID-19 preventive measures to maximize the protection against infection. Multiple preventive behavior must be practiced within all aviation industry stakeholders and entities. It's very important that everybody takes its own personal and shared responsibilities for preventing the spread of infection seriously. Finally, such models serve as a great reminder that the many preventive behaviors that we put in place every day have their imperfections on an individual basis and are not perfect alone. However, collectively they are very effective in giving everybody greater protection against infection with COVID-19.

\section{Reference}

1. ACI Europe. COVID-19: Statements, Facts and Figures, Airports Council International Europe, Brussels, Belgium, March 2021.

2. Alexandre de Juniac. SKYWAY - Supporting European Aviation, Autumn/Winter Edition 2020, p.20-23, EUROCONTROL, Brussels, Belgium, November 2020.

3. Benjamin Smith. SKYWAY - Supporting European Aviation, Autumn/Winter Edition 2020, p.10-11, EUROCONTROL, Brussels, Belgium, November 2020.

4. EASA. EASA-ECDC COVID-19 Aviation Health Safety Protocol, European Union Aviation Safety Agency, Cologne, Germany, June 2020.

5. EUROCONTROL. Impact assessment of COVID-19 measures on airport performance, Airport Research Center - EUROCONTROL, Belgium, October 2020.

6. EUROCONTROL. STATFOR Reports 2020, EUROCONTROL, Brussels, Belgium, March 2021.

7. Henrik Hololei. SKYWAY - Supporting European Aviation, Autumn/Winter Edition 2020, p.12-15, EUROCONTROL, Brussels, Belgium, November 2020.

8. IATA. European Air Transport COVID-19 Impacts and Recovery, International Air Transport Association, Montreal, Quebec - Canada, 10 December 2020.

9. Siobhan Roberts. The Swiss Cheese Model of Pandemic Defense, The New York Times, The New York Times Company, New York, NY 10018, 7 December 2020. 